\title{
Mono-Isocentric Technique in the Breast Cancer and Organ at Risk Tolerance
}

\author{
Assaoui $\mathrm{F}^{\text {** }}$, Toulba $\mathrm{A}^{2 *}$, Nouh $\mathbf{M}^{2}$, Lkhouyaali $\mathrm{S}^{2}$, Bensouda $\mathrm{Y}^{2}$, Kebdani $\mathrm{T}^{2}$ and Benjaafar $\mathrm{N}^{2}$
}

${ }^{1}$ Medical Physics Unit, Radiotherapy Department, National Institute of Oncology, Rabat, Morocco

${ }^{2}$ Department of Radiation Oncology, National Institute of Oncology, Rabat, Morocco

\begin{abstract}
Purpose: To investigate the impact of the single-isocentre technique on the volumetric dose of lung and heart for adjuvant radiation in breast cancer with regional nodal.

Methods and materials: Thirty patients treated for breast cancer with supraclavicular fossa irradiation; two techniques of treatment TMT (Traditional Matching Technique) and MIT (Mono-Isocentric Technique) are compared, TMT (tangents in SAD and supraclavicular (SCL) in SSD: Source Skin Distance) and MIT (the all fields in SAD: Source Axe Distance) (Chart 1). Techniques were compared according to dose volume histograms (DVHs) analysis in terms of PTV homogeneity and as OARs (Organs at Risk) dose and volume parameters.

Results: The dose distribution in PTV is similar in the both techniques TMT and MIT but with hot spots in the junction of the three fields for the TMT (average $120 \%$ for TMT and $110 \%$ for MIT). The analysis of DVHs shows a decrease in the mean OARs. Lung and heart dose is improved using the MIT and with significant difference in the V20 and V30 for the lung and in the V10 and V40 for the heart.

Conclusions: The results of our study demonstrated that the target volumes were sufficiently irradiated with the MIT and the lung and heart volumes irradiated were small. Furthermore, it should not be over or under dose in the supraclavicular and tangential junction.
\end{abstract}

Keywords: Breast cancer; Supraclavicular; 3-D conformal radiation therapy; Mono-isocentric technique

\section{Introduction}

Breast cancer will afflict 1 of every 9 women [1]. Improvements in local control with locoregional radiotherapy after surgery for breast cancer in patients at risk for locoregional recurrence have been demonstrated in randomized trials, showed that the 10 years locoregional recurrence rate was $13 \%$ in patients with 1 to 3 positive axillary lymph nodes, $29 \%$ in patients with at least 4 positive nodes and in breast conservation management $[2,3]$. However, survival benefits were not demonstrated until recently [4,5]. It is postulated that no increase in survival was seen in the earlier trials secondary to excessive myocardial doses, especially with left-sided breast cancers and internal mammary chain (IMC) irradiation [6,7]. A report from Canada described a $2 \%$ incidence of fatal cardiac toxicity for left side breast radiation and $1 \%$ from right side radiation [8]. Additionally, as much as $9 \%$ of irradiated breast cancer patients suffer from radiation-induced lung sequelae $[6,9]$.

The radiation mortality and morbidity are technique- and dose-volume dependent. Optimized radiation treatment planning plays a critical role in the care of breast cancer patients. Dosimetry planning in breast carcinoma has evolved from evaluation of dose distribution in a single plane (i.e., 2 dimensional [2D] planning) to CT-based 3-dimensional radiotherapy (3DCRT) planning, to intensity modulated radiotherapy (IMRT) [10,11]. The conventional tangential technique uses proper selection of wedge and beam angle based on a single central axis isodose distribution. Although high local control can be achieved, it results in large hot spots, dose non-uniformities and excessive exposure of normal tissue [12,13]. 3-D conformal radiation therapy (3D CRT) and intensity-modulated radiation therapy (IMRT), treatment planning and delivery improved greatly. Many planning studies have shown that 3D CRT is superior to CR [14,15].
The international "Gold Standard" radiotherapy fractionation remains $50 \mathrm{~Gy}$ in 1.8-2.0 Gy per fraction, with or without a boost.

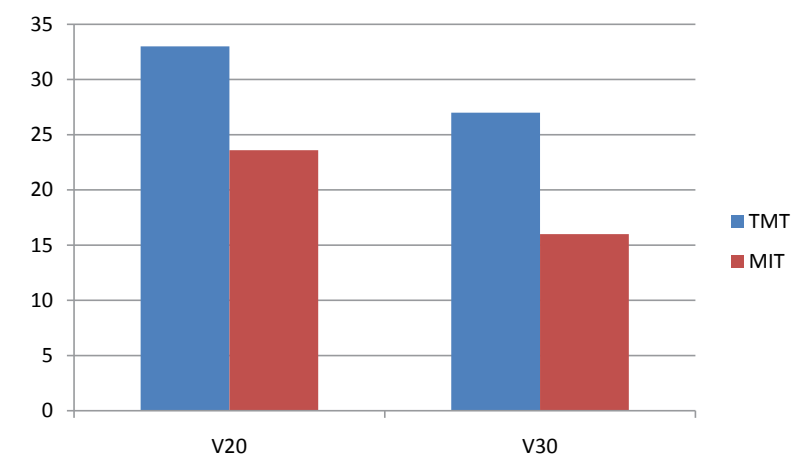

This graph shows the decrease of the percent of the volume received 20 Gy and 30 Gy by using the MIT

Chart 1: The percent of the lung volume received 20 Gy and 30 Gy for TMT and MIT.

*Corresponding authors: Fatima Assaoui, Medical Physics Unit, Radiotherapy Department, National Institute of Oncology, Rabat, Morocco, E-mail: Assaoui2003@yahoo.fr

Ahmedou Toulba, Department of Radiation Oncology, National Institute of Oncology, Rabat, Morocco, E-mail: Ahmedoux@gmail.com

Received July 24, 2012; Accepted August 25, 2012; Published August 30, 2012

Citation: Assaoui F, Toulba A, Nouh M, Lkhouyaali S, Bensouda Y, et al. (2012) Mono-Isocentric Technique in the Breast Cancer and Organ at Risk Tolerance. $J$ Nucl Med Radiat Ther S2:010. doi:10.4172/2155-9619.S2-010

Copyright: $\odot 2012$ Assaoui F, et al. This is an open-access article distributed unde the terms of the Creative Commons Attribution License, which permits unrestricted use, distribution, and reproduction in any medium, provided the original author and source are credited. 
However, recent data suggest that hypofractionated regimes may provide a viable alternative to this standard approach. These results potentially offer treatment with similar clinical outcomes but with clear potential benefits in terms of cost savings for both radiotherapy departments and patients $[16,17]$.

The purpose of this study was to evaluate the advantages of the single-isocentre technique for adjuvant radiation in breast cancer with regional nodal by analyzing the difference in dose uniformity, planning target volume (PTV) coverage, exposure of organs at risk (OAR).

\section{Material and Methods}

Data of thirty left and right sided breast cancer patients with supraclavicular irradiation, 8 of them had breast conserving therapy and 22 Radical mastectomy, were retrospectively included in this study. The median age was 43 (range 25 years - 64 years). We used accelerated radiotherapy over a shortened time period. All patients were administered 15 fractions of 2.8 Gy (total dose 42 Gy). An additional dose $11.2 \mathrm{~Gy}$ (the so called boost) was applied to the posttumorectomy site in the 8 patients.

In all cases the CT-X ray simulation (Siemens Simulator Scanner 16 barrettes and FOV of $82 \mathrm{~cm}$ ) was used. The patients are placed supine in a halfbody Vac-lok bag on the scanner table and the both arms placed above the head which is tattled backwards and rotating to the controlateral side. Three fiducial markers are placed in anatomically stable regions, one anterior as reference for the isocenter and two lateral points to assure identical positioning of the patient (laser beams) during computed tomography and irradiation. The scans extended from the supraclavicular region to the most caudal part of the lungs with a $5 \mathrm{~mm}$ slice separation. For our study, the treatment fields for the both techniques: traditional matching technique (TMT) and mono isocentric technique (MIT) were defined by using the CT data for all patients.

After the scans have been acquired they are transferred over the network to the treatment planning system and a treatment plan is generated. Treatment planning was performed using the treatment planning system XIO version 4.6. The doses are calculated using heterogeneity corrections and the beams are weighted so that the prescription isodose line encircles most of the PTV.

The contouring of the target volumes, lung and heart were defined in the Focal System using the CT data.

In our department the treatment planning was performed by the Physicist and consisted of setting the beams entries angles, the field's sizes, the shields shapes, the isocenter position and wedge angle in order to provide them maximally homogenous dose within the PTV. Dose to volume histograms, were applied for both techniques in order to assess the homogeneity of the doses and for the choice of isodose distribution.

\section{Traditional matching technique treatment plan}

The fields were set-up on the treatment planning system using the radio opaque markers visible in the CT-slices and the treatment parameters recorded on the patient treatment chart. An anterior photon field ( $\mathrm{SSD}=100 \mathrm{~cm}$, Energy $6 \mathrm{MV}$ ), generated by Clinac Elekta, is used to irradiate the medial lymph nodes which is rotated by 10 degrees in order to avoid the spinal cord and the esophagus. Furthermore, one block was drawn to protect the larynx. Two tangential photon (6 MV) fields (SAD i.e SSD $<100 \mathrm{~cm}$ ) are used to irradiate the breast, that there is at $2 \mathrm{~cm}$ of the flash above the breast parenchyma and the dorsal edges are made coplanar to decrease the amount of the lung tissue irradiated, no more than $2-3 \mathrm{~cm}$ of the lung are included in the treatment field. The three fields (tangential and supraclavicular) are traditional matching then over and under doses in the junction, using collimator and wedge.

\section{Mono isocentric technique treatment plan}

Marking of the isocenter was the first of planning by using the $\mathrm{X}$-ray simulation. The horizontal line crossing this point formed the border between the supraclavicular and the asymmetric tangential fields. The three photon $6 \mathrm{MV}$ fields (supraclavicular and tangential) were on SAD depending on the position of the isocenter; the collimator angle was always 0 degree because a breast board was used.

The anterior field, irradiated with the upper quarter of the beam, encompassed the supraclavicular. The gantry was rotated laterally by 10 degrees in order to avoid the spinal cord and the esophagus. And one block to shield the larynx was placed. The breast was irradiated from two tangential fields (lower quarter beam) and lower border of the treatment area was positioned $2 \mathrm{~cm}$ below the sub mammary position. The gantry varied from patient to other in order to cover all the PTV and to exclude the controlateral breast. The organs at risk lung and heart were maximally shielded with MLC. When the plan of treatment was accepted the next step was to perform it on the Clinac Elekta. The patient was placed in the same position as on the scanner simulator and during the computed tomography, using the pre-tattooed points and the laser beams. We us the shifts that were determined at the time of virtual simulation to move the patient to the intended beam isocenter and the AP and lateral SSDs for the beam isocenter are verified. The isocenter was found and marked on the patient's skin at the junction regions of the superclavicular field and mammary field. Portal images (PI) were made for all patients when a new course of treatment was begun and then one time after 6 fractions.

\section{Data analysis and statistical study}

Dose-volume histograms (DVHs) were computed for the breast and the regional nodal target volumes and the organs at risk (lung and heart). For the target volumes the over doses of the reference dose were compared between the TMT and MIT. The mean doses of the lung and the heart were also compared between both the techniques. The fraction of the lung volume receiving $20 \mathrm{~Gy}-30 \mathrm{~Gy}$ were computed and compared between TMT and MIT by using the test of student method (the value $p$ is significant $p \leq 0.05$ ) (Chart 2). The volume of the heart receiving $10 \mathrm{~Gy}$ and $40 \mathrm{~Gy}$ were computed and compared for TMT and MIT. We have chosen 10 Gy to show that there is distinct difference

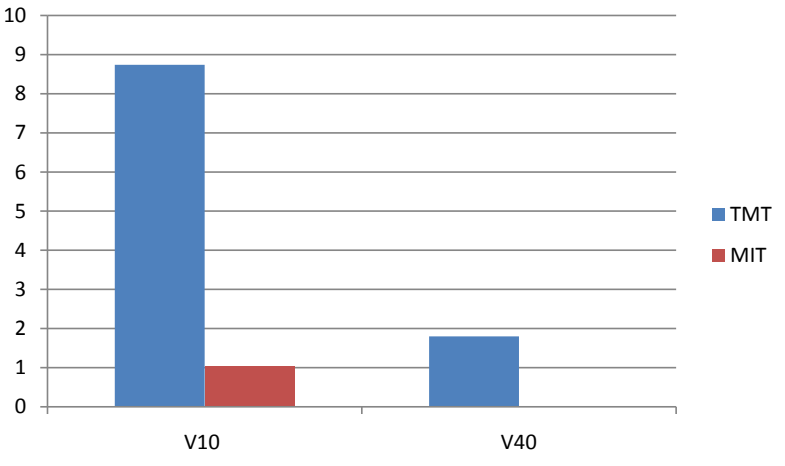

Chart 2: The percent of the lung volume received 20 Gy and 30 Gy for TMT and MIT. 
between the two techniques in this dose region. The volume receiving a dose of $40 \mathrm{~Gy}$ or more represents the high dose volume.

\section{Results}

The dose distribution in the breast is similar in the both techniques TMT and MIT (Figure 1).

The DVHs of the target volumes breast and supraclavicular did not differ much between patients and no significant difference exists between the dose coverage of the breast using the TMT and the MIT (Figure 2).

The average of the hot spots $120 \%$ is present in the TMT in the junction of the suparclavicular field and the tangential fields. With the mono isocentric technique the maxima of the hot spots in the junction of the three fields is $110 \%$ and in the range $110-115 \%$ in the breast, then the target coverage is improved (Table 1).

\section{Organs at risk}

For the DVHs of the organs at risk lung and heart, the difference between the TMT and the MIT is significant. An average DVHs of these volumes is representative for the all patients in the both techniques (Figure 3).

\section{Lung}

An increase in the mean lung dose is improved using the MIT (Table 2).

The mean lung dose was on average $10.93 \mathrm{~Gy}$ (range: $7.8 \mathrm{~Gy}-16.5$ Gy) and 8.24 Gy (range: 4.47 Gy -12.05 Gy) for the TMT and MIT, respectively.

We also analysed the mean percents of the lung volumes receiving 20 Gy (i.e V20) and 30 Gy (V30) for each patient with the both techniques (Table 3 ).

The difference between the TMT and the MIT is statistically significant for mean dose, V20 and V30 regardless of the surgical treatment.

\section{Heart}

The heart receives fewer doses using the MIT (Table 4).

The percents of the heart volumes receiving at least $10 \mathrm{~Gy}$ and 40 Gy were analyzed.

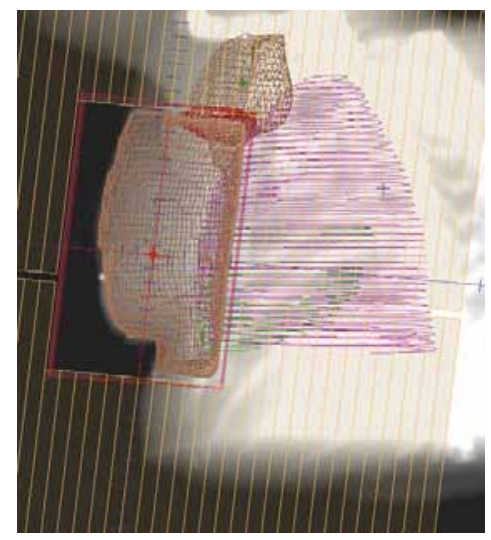

Figure 1: Dose distributions for TMT in DRRs.

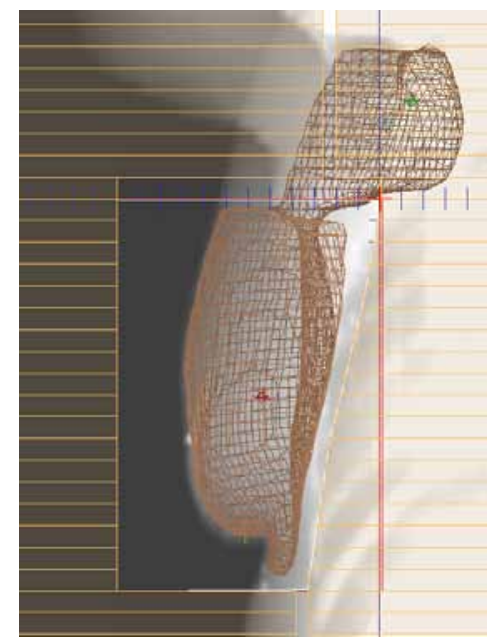

Figure 2: Dose distributions for MIT in DRRs.

\begin{tabular}{|c|c|c|}
\hline \multirow[b]{2}{*}{ Patient } & \multicolumn{2}{|c|}{ MAXIMUM DOSE IN THE JUNCTION (Gy) } \\
\hline & TMT & MIT \\
\hline 1 & 479 & 441 \\
\hline 2 & 55.3 & 45.4 \\
\hline 3 & 52.3 & 45.6 \\
\hline 4 & 52.3 & 47 \\
\hline 5 & 53.6 & 44 \\
\hline 6 & 54.7 & 48 \\
\hline 7 & 53.4 & 46.3 \\
\hline 8 & 49.4 & 45.4 \\
\hline 9 & 53.1 & 44.2 \\
\hline 10 & 54.4 & 47.2 \\
\hline 11 & 52 & 43 \\
\hline 12 & 55 & 47 \\
\hline 13 & 54 & 43 \\
\hline 14 & 48.5 & 44.5 \\
\hline 15 & 52 & 45 \\
\hline 16 & 49 & 43 \\
\hline 17 & 49 & 43 \\
\hline 18 & 53 & 47 \\
\hline 19 & 52.3 & 46.2 \\
\hline 20 & 51.8 & 46.8 \\
\hline 21 & 49.6 & 40.7 \\
\hline 22 & 54 & 49 \\
\hline 23 & 52 & 47 \\
\hline 24 & 56 & 45 \\
\hline 25 & 50.3 & 49 \\
\hline 26 & 46.6 & 44.1 \\
\hline 27 & 54.4 & 49 \\
\hline 28 & 52.4 & 44.4 \\
\hline 29 & 51.2 & 46.9 \\
\hline 30 & 54.5 & 47.1 \\
\hline Mean & 52.1333333 & 45.5966667 \\
\hline
\end{tabular}

Table 1: Dose in the Supraclavicular and Tangential Fields Junction for the TMT and MIT.

The patients with the left breast cancer, heart volume are receiving a dose of $40 \mathrm{~Gy}$ was on average $1.8 \%$ (range: $0 \%-4.8 \%$ ) and $0 \%$ for the TMT and MIT, respectively. For a dose of 10 Gy these figures are average $8.7 \%$ (range: $1.26 \%-16.2 \%$ ) and $1.04 \%$ (range: 0\%-7.2\%).

The mean percents using the MIT are inferior to the TMT and significant for V10 and V40 (Table 5). 
Citation: Assaoui F, Toulba A, Nouh M, Lkhouyaali S, Bensouda Y, et al. (2012) Mono-Isocentric Technique in the Breast Cancer and Organ at Risk Tolerance. J Nucl Med Radiat Ther S2:010. doi:10.4172/2155-9619.S2-010

Page 4 of 5

On the other hand, the work load and time necessary for treatment planning using the MIT was greater than in the planning of the TMT. However, the irradiation time necessary for the application of one fraction was shorter in the MIT, as there was no need to reposition the therapeutic table then to minimise the set-up errors and all these increase the reproducibility.

\section{Discussion}

In some clinical situations breast or chest wall radiotherapy with

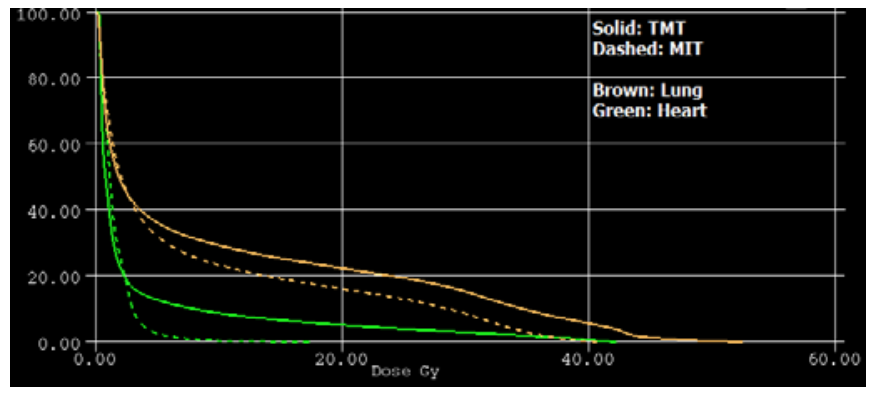

Figure 3: OARs DVH.

\begin{tabular}{|l|l|l|l|}
\hline & TMT & MIT & P value \\
\hline V20 (mean) & $33 \% \%$ & $235 \%$ & $<0.05$ \\
\hline V30(mean) & $27 \%$ & $16 \%$ & $<0.05$ \\
\hline
\end{tabular}

Table 2: Lung comparison between V20 and V30 in both techniques.

\begin{tabular}{|c|c|c|c|}
\hline & PATIENTS & MEAN LUNG DOSE (GY) TMT & MIT \\
\hline \multirow{8}{*}{$\begin{array}{l}\text { BREAST } \\
\text { CONSERVING }\end{array}$} & 1 & 9.6 & 7.39 \\
\hline & 2 & 10.73 & 8.39 \\
\hline & 3 & 10 & 8.6 \\
\hline & 4 & 9.8 & 7.5 \\
\hline & 5 & 9.68 & 5.97 \\
\hline & 6 & 7.8 & 4.47 \\
\hline & 7 & 10.58 & 6.34 \\
\hline & 8 & 10.97 & 7.42 \\
\hline \multirow{22}{*}{$\begin{array}{l}\text { RADICAL } \\
\text { MASTECTOMY }\end{array}$} & 9 & 10.47 & 7.43 \\
\hline & 10 & 10.32 & 8.66 \\
\hline & 11 & 9.57 & 6.1 \\
\hline & 12 & 7.76 & 5.78 \\
\hline & 13 & 10.6 & 6.94 \\
\hline & 14 & 14.33 & 12.66 \\
\hline & 15 & 16.41 & 10.29 \\
\hline & 16 & 10.12 & 6.61 \\
\hline & 17 & 14.7 & 10.19 \\
\hline & 18 & 13.72 & 8.59 \\
\hline & 19 & 11.21 & 10.17 \\
\hline & 20 & 9.54 & 11.07 \\
\hline & 21 & 10.2 & 7.84 \\
\hline & 22 & 9.93 & 6.1 \\
\hline & 23 & 10.58 & 7.85 \\
\hline & 24 & 8.36 & 6.64 \\
\hline & 25 & 10.11 & 8.39 \\
\hline & 26 & 10.52 & 8.8 \\
\hline & 27 & 11.91 & 10.7 \\
\hline & 28 & 11.29 & 9.52 \\
\hline & 29 & 10.78 & 8.88 \\
\hline & 30 & 16.57 & 12.05 \\
\hline
\end{tabular}

Table 3: The Lung's Mean Doses of the all Patients on Function of the Both Techniques TMT and MIT.

\begin{tabular}{|l|l|l|l|l|}
\hline Patients & V10 TMT (\%) & V10 MIT (\%) & V40 TMT (\%) & V40 MIT (\%) \\
\hline 1 & 1.2 & 0 & 0 & 0 \\
\hline 2 & 8.4 & 0 & 0 & 0 \\
\hline 3 & 1.3 & 0 & 0 & 0 \\
\hline 4 & 2 & 0 & 0 & 0 \\
\hline 5 & 11.4 & 0 & 2.4 & 0 \\
\hline 6 & 8.4 & 1.2 & 1.2 & 0 \\
\hline $\mathbf{7}$ & 12 & 1.2 & 3.6 & 0 \\
\hline $\mathbf{8}$ & 7 & 1.2 & 0 & 0 \\
\hline $\mathbf{9}$ & 15.6 & 7.2 & 2.4 & 0 \\
\hline 10 & 1.2 & 0 & 0 & 0 \\
\hline 11 & 9.6 & 1.2 & 3.6 & 0 \\
\hline 12 & 16.2 & 0 & 4.8 & 0 \\
\hline 13 & 14.4 & 2.4 & 4.2 & 0 \\
\hline 14 & 12.8 & 1.2 & 3.6 & 0 \\
\hline 15 & 9.6 & 0 & 1.2 & 0 \\
\hline Mean & 8.74 & 1.04 & 1.8 & 0 \\
\hline
\end{tabular}

Table 4: Mean heart dose for the TMT and the MIT for patient with left-sided breast cancer.

\begin{tabular}{|l|l|l|l|}
\hline & TMT & MIT & P value \\
\hline V10 (mean) & $8.74 \%$ & $1.8 \%$ & $<0.05$ \\
\hline V40 (mean) & $1.04 \%$ & $0 \%$ & $<0.05$ \\
\hline
\end{tabular}

Table 5: Heart comparison between $\mathrm{V} 10$ and $\mathrm{V} 20$ in both techniques.

supraclavicular irradiation is uesd to improve local control. Often the treatment is delivered by two tangential fields to the breast or chest wall and an anterior field that irradiates the supraclavicular region. The tissue between the breast or chest wall and the supraclavicular region may be under or overdosed, because of the junction between the two tangential fields and the anterior field, therefore there was an increase of toxicity or tumor control probability reduced $[18,19]$.

An important factor affecting the complication rate is the radiation technique. Many ways have been reported including matching fields using shielding blocks, multi leaf collimators (MLC) or independent asymmetric jaws to irradiate the target volumes i.e., breast and region nodal and to minimize the dose in the organs at risk [20-22].

Previous studies have reported that the wedged tangential field technique has dose nonuniformity of around $15-20 \%$ in the superior and inferior regions of the breast [23,24]. In addition, the medial and lateral aspects of the breast may also be exposed to higher doses of radiation because of lower attenuation of lung tissue in the treatment field $[14,25]$. Furthermore, because the breast is close to critical organs lungs and the heart, it is not easy to attain homogeneous dose distribution using the wedged tangential field technique. Therefore, various radiation therapy methods were studied to solve these problems $[23,26]$.

In our study, the analysis of the TMT and MIT results show that with one isocenter for all the fields and with the MLC the dose in organs at risk is lower, for example $1.8 \%$ of the heart volume received $10 \mathrm{~Gy}$ and V40 on $0 \%$, without affecting the local control, the target volumes received at least $95 \%$ of the prescription. From the statistical study of this work we deduced that the decrease of the dose in OAR is very important. The increase of the dose in the lung is due to a large part of the lung being irradiated in the TMT and the part which receives a high dose due to the tangential fields is usually smaller for the MIT. We also deduced that DVH of the supraclavicular and OAR vary considerably between the patients due to their different anatomy and body outline not just between the techniques. 
Citation: Assaoui F, Toulba A, Nouh M, Lkhouyaali S, Bensouda Y, et al. (2012) Mono-Isocentric Technique in the Breast Cancer and Organ at Risk Tolerance. J Nucl Med Radiat Ther S2:010. doi:10.4172/2155-9619.S2-010

Several studies showed that the mono isocentric technique in the breast cancer, the reproducibility of positioning is simple and precise then the time consuming of everyday therapeutic sessions decrease while the work load of the treatment plan increase [27-29].

\section{Conclusion}

The mono isocentric technique decreases the dose in organs at risk, lung and heart, and allows the avoidance of the cold and the hot spots. The reduction of the execution time of the daily workload Linac was achieved. The reproducibility of positioning is precise and simple.

\section{References}

1. Jemal A, Murray T, Ward E, Samuels A, Tiwari RC, et al. (2005) Cancer statistics, 2005. CA Cancer J Clin 55: 10-30.

2. (1995) Effects of radiotherapy and surgery in early breast cancer. An overview of the randomized trials. Early Breast Cancer Trialists' Collaborative Group. N Engl J Med 333: 1444-1455.

3. Fisher B, Jeong JH, Anderson S, Bryant J, Fisher ER, et al. (2002) Twentyfive-year follow-up of a randomized trial comparing radical mastectomy, total mastectomy, and total mastectomy followed by irradiation. N Engl J Med 347 : 567-575.

4. Recht A, Gray R, Davidson NE, Fowble BL, Solin LJ, et al. (1999) Locoregional failure 10 years after mastectomy and adjuvant chemotherapy with or without tamoxifen without irradiation: experience of the Eastern Cooperative Oncology Group. J Clin Oncol 17: 1689-1700.

5. Overgaard M, Hansen PS, Overgaard J, Rose C, Andersson M, et al. (1997) Postoperative radiotherapy in high-risk premenopausal women with breast cancer who receive adjuvant chemotherapy. Danish Breast Cancer Cooperative Group 82b Trial. N Engl J Med 337: 949-955.

6. Hurkmans CW, Borger JH, Bos LJ, van der Horst A, Pieters BR, et al. (2000) Cardiac and lung complication probabilities after breast cancer irradiation. Radiother Oncol 55: 145-151.

7. Dogan MH, Zincircioglu SB, Zorlu F (2009) Comparison of various radiation therapy techniques in breast cancer where target volume includes mammaria interna region. Med Dosim 34: 42-50.

8. Paszat LF, Mackillop WJ, Groome PA, Schulze K, Holowaty E (1999) Mortality from myocardial infarction following postlumpectomy radiotherapy for breas cancer: a population-based study in Ontario, Canada. Int J Radiat Oncol Biol Phys 43: 755-762.

9. Nishioka A, Ogawa Y, Hamada N, Terashima M, Inomata T, et al. (1999) Analysis of radiation pneumonitis and radiation-induced lung fibrosis in breast cancer patients after breast conservation treatment. Oncol Rep 6: 513-517.

10. Caudell JJ, De Los Santos JF, Keene KS, Fiveash JB, Wang W, et al. (2007) A dosimetric comparison of electronic compensation, conventional intensity modulated radiotherapy, and tomotherapy in patients with early-stage carcinoma of the left breast. Int J Radiat Oncol Biol Phys 68: 1505-1511.

11. Harsolia A, Kestin L, Grills I, Wallace M, Jolly S, et al. (2007) Intensity-modulated radiotherapy results in significant decrease in clinical toxicities compared with conventional wedge-based breast radiotherapy. Int J Radiat Oncol Biol Phys 68: $1375-1380$

12. Buchholz TA, Gurgoze E, Bice WS, Prestidge BR (1997) Dosimetric analysis of intact breast irradiation in off-axis planes. Int J Radiat Oncol Biol Phys 39: 261-267.

13. Taylor ME, Perez CA, Halverson KJ, Kuske RR, Philpott GW, et al. (1995) Factors influencing cosmetic results after conservation therapy for breast cancer. Int J Radiat Oncol Biol Phys 31: 753-764.

14. Vicini FA, Sharpe M, Kestin L, Martinez A, Mitchell CK, et al. (2002) Optimizing breast cancer treatment efficacy with intensity-modulated radiotherapy. Int $\mathrm{J}$ Radiat Oncol Biol Phys 54: 1336-1344.

This article was originally published in a special issue, Surgical Oncology Clinical Importance handled by Editor(s). Dr. Liqiang Zhang, Arizona State University, USA; Dr. Salomone Di Saverio, Surgery and Trauma Surgery Unit, Italy
15. Ohashi T, Takeda A, Shigematsu N, Fukada J, Sanuki N, et al. (2009) Dose distribution analysis of axillary lymph nodes for three-dimensional conformal radiotherapy with a field-in-field technique for breast cancer. Int J Radiat Oncol Biol Phys 73: 80-87.

16. Whelan TJ, Kim DH, Sussman J (2008) Clinical experience using hypofractionated radiation schedules in breast cancer. Semin Radiat Oncol 18 257-264.

17. START Trialists' Group, Bentzen SM, Agrawal RK, Aird EG, Barrett JM, et al. (2008) The UK Standardisation of Breast Radiotherapy (START) Trial B of radiotherapy hypofractionation for treatment of early breast cancer: a randomised trial. Lancet 371: 1098-1107.

18. Miles EA, Venables K, Hoskin PJ, Aird EG, START Trial Management Group (2009) Dosimetry and field matching for radiotherapy to the breast and supraclavicular fossa. Radiother Oncol 91: 42-48.

19. Lu XQ, Sullivan S, Eggleston T, Holupka E, Bellerive M, et al. (2003) A three-field breast treatment technique with precise geometric matching using multileaf collimator-equipped linear accelerators. Int J Radiat Oncol Biol Phys 55: $1420-1431$

20. Conte G, Nascimben O, Turcato G, Polico R, Idi MB, et al. (1988) Three-field isocentric technique for breast irradiation using individualized shielding blocks. Int J Radiat Oncol Biol Phys 14: 1299-1305.

21. Klein EE, Taylor M, Michaletz-Lorenz M, Zoeller D, Umfleet W (1994) A mono isocentric technique for breast and regional nodal therapy using dua asymmetric jaws. Int J Radiat Oncol Biol Phys 28: 753-760.

22. Hernandez V, Arenas M, Pons F, Sempau J (2011) Clinical applications of geometrical field matching in radiotherapy based on a new analytical solution. Med Dosim 36: 160-165.

23. Moon SK, Kim YS, Kim SY, Lee MJ, Keum HS, et al. (2011) A dosimetric analysis of IMRT and multistatic fields techniques for left breast radiotherapy. Med Dosim 36: 276-283.

24. Chin LM, Cheng CW, Siddon RL, Rice RK, Mijnheer BJ, et al. (1989) Threedimensional photon dose distributions with and without lung corrections fo tangential breast intact treatments. Int J Radiat Oncol Biol Phys 17: 1327-1335.

25. Kestin LL, Sharpe MB, Frazier RC, Vicini FA, Yan D, et al. (2000) Intensity modulation to improve dose uniformity with tangential breast radiotherapy: initial clinical experience. Int J Radiat Oncol Biol Phys 48: 1559-1568.

26. Hong L, Hunt M, Chui C, Spirou S, Forster K, et al. (1999) Intensity-modulated tangential beam irradiation of the intact breast. Int J Radiat Oncol Biol Phys 44: $1155-1164$

27. Kong FM, Klein EE, Bradley JD, Mansur DB, Taylor ME, et al. (2002) The impac of central lung distance, maximal heart distance, and radiation technique on the volumetric dose of the lung and heart for intact breast radiation. Int J Radiat Oncol Biol Phys 54: 963-971.

28. Aref A, Thornton D, Youssef E, He T, Tekyi-Mensah S, et al. (2000) Dosimetric improvements following 3D planning of tangential breast irradiation. Int J Radiat Oncol Biol Phys 48: 1569-1574.

29. Edlund T, Gannett D (1999) A single isocenter technique using CT-based planning in the treatment of breast cancer. Med Dosim 24: 239-245. 